\title{
Tuning Fork-Shaped Microsurgical Venous Anastomosis in Selective Cases of Head \& Neck Reconstruction
}

\author{
Rajan Arora ${ }^{1, \odot}$ Kripa Shankar Mishra ${ }^{1, \odot}$ Hemant T. Bhoye ${ }^{1} \quad$ Ravi K. Singh ${ }^{1, \odot}$ Ravikiran Naalla
}

$1^{1}$ Reconstructive Microsurgery Unit, Department of Surgical Oncology, Rajiv Gandhi Cancer Institute \& Research Centre, Rohini, New Delhi, India

Indian J Plast Surg:2021;54:97-98.

The paucity of neck vessels is a common problem in patients with previous surgery, radiotherapy with or without chemotherapy. Vessel-depleted neck is a well-known entity. ${ }^{1,2}$ However, on several occasions, we manage to find a ligated internal jugular vein stump as a recipient vein.

As a unit policy, we perform single venous anastomosis only. We perform a second vein anastomosis only if the venous drainage through single venous anastomosis is insufficient, based on clinical judgment. It is not uncommon to encounter a paucity of veins and the requirement to do double venous anastomosis.

In such uncommon circumstances, we found this technique is useful.

Tuning fork-shaped anastomosis involves separate anastomosis of two donor veins to a single recipient vein in an end-to-end fashion.

Technique: The first vein is anastomosed at the farther end of the recipient vein (-Fig. 1). The posterior layer is sutured first, followed by the anterior layer. The near corner stitch of the anastomosis was done as shown in - Fig. $\mathbf{2}$.
Address for correspondence Dr. Ravikiran Naalla, MS, MCh, Attending Consultant, Room no- 3064, Reconstructive Microsurgery Unit, Department of Surgical Oncology, Rajiv Gandhi Cancer Institute \& Research Centre, Sir Chotu Ram Marg, Sector-5, Rohini Institutional Area, Rohini, New Delhi, Delhi-110085, India (e-mail: ravi_2488@yahoo.co.in).

The second vein is then placed at the near end of the recipient vein and the anastomosis was completed similarly. The residual opening (between the two donor veins) in the recipient vein was closed with few interrupted sutures.

Although the indications for this technique is very rare, it is a promising solution in critical situations. In our experience, with over 1700 free flaps for head and neck reconstruction during the last 5 years, we have utilized this anastomosis technique in 11 patients. Seven patients underwent anterolateral thigh flaps, and four patients underwent radial forearm free flaps. All of them had an uncomplicated recovery. The ligated stump of the internal jugular vein was the only recipient vein in all 11 patients. Hence, as a prerequisite to perform this technique, the size mismatch between the donor and recipient veins must be $\geq 3: 1$. This technique is also beneficial for surgeons who prefer to perform two venous anastomoses in all cases. However, in vessel-depleted neck, we prefer to use vein grafts to access the contralateral neck vessels. The disadvantage of this technique is a steep learning curve. published online

February 22, 2021
DOI https://doi.org/

10.1055/s-0041-1723907

ISSN 0970-0358. (c) 2021. Association of Plastic Surgeons of India.

This is an open access article published by Thieme under the terms of the Creative Commons Attribution-NonDerivative-NonCommercial-License, permitting copying and reproduction so long as the original work is given appropriate credit. Contents may not be used for commercial purposes, or adapted, remixed, transformed or built upon. (https://creativecommons.org/licenses/by-nc-nd/4.0/).

Thieme Medical and Scientific Publishers Pvt. Ltd. A-12, 2nd Floor, Sector 2, Noida-201301 UP, India 

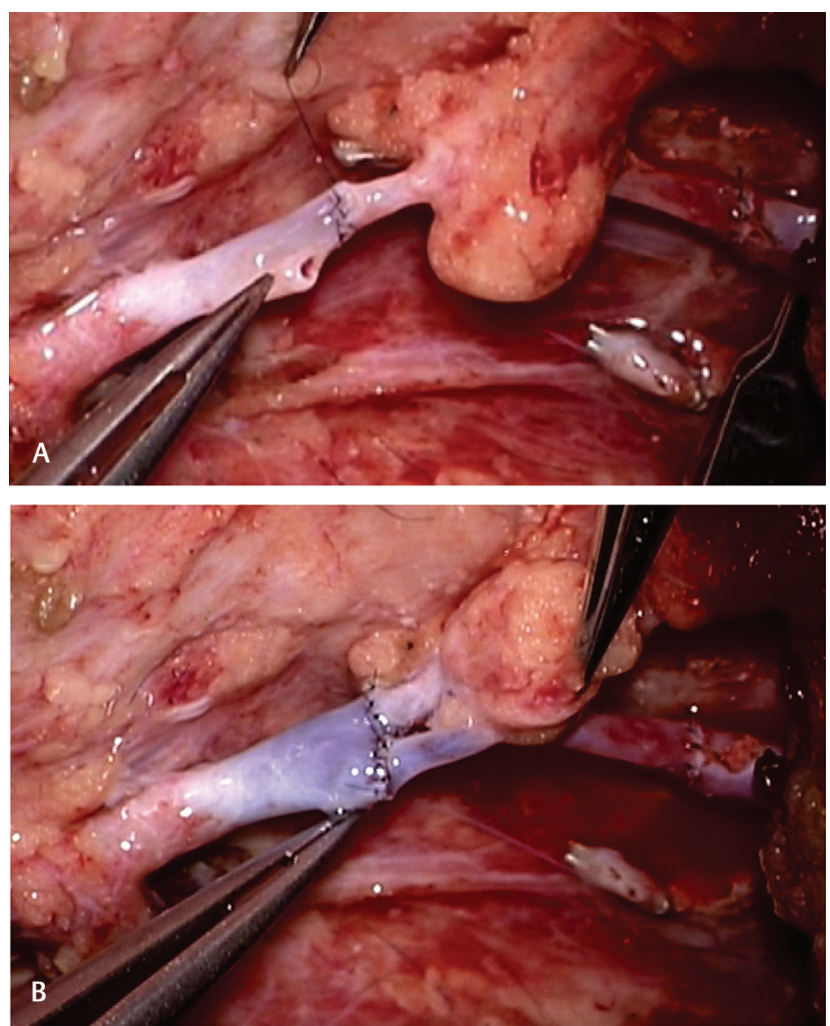

Fig. 1 Image showing a tuning fork-shaped venous anastomosis. (A) One of the donor veins anastomosed at the farther end of the recipient vein. (B) After anastomosis of both donor veins.
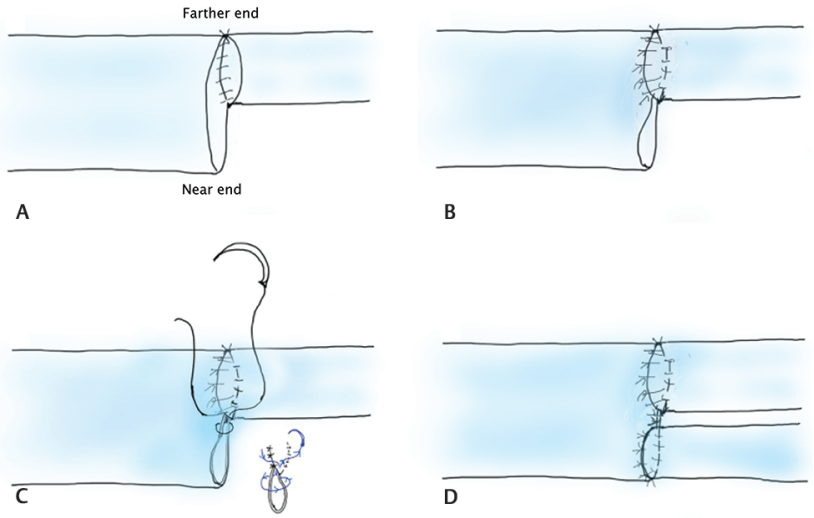

Fig. 2 Line diagram showing the technique of anastomosis. (A) The anastomosis of the posterior wall of the first donor vein at the farther end of the recipient vein. (B) Anterior wall sutures. (C) Corner stitch for the completion of the first donor vein. (D) Final appearance.

\section{Conflicts of Interest}

None declared.

\section{References}

1 Mahendru S, Singh H, Sarin D, et al. Microvascular free tissue transfer in vessel compromised neck: techniques and recommendations. Int Microsurg J 2019;3:2

2 Ahmadi I, Herle P, Rozen WM, Leong J. One versus two venous anastomoses in microsurgical free flaps: a meta-analysis. J Reconstr Microsurg 2014;30(6):413-418 